\title{
O PAPEL DA INTERFACE PÚBLICO/PRIVADA NA VIDA URBANA O Bairro Torre, João Pessoa/PB, Brasil
}

The Role of Public/Private Interface in Urban Life The Neighborhood Torre, in João Pessoa/PB, Brazil

\author{
Barbosa de Aquino, Caroline; \\ (Departamento de Arquitetura, Universidade Federal da Paraíba) carolinebarbosadeaquino@gmail.com \\ Trigueiro de Araújo Morais, Marcele \\ (Departamento de Arquitetura, Universidade Federal da Paraíba) marcele.trigueiro@gmail.com
}

\section{RESUMEN}

Este artigo é extraído de um trabalho de conclusão de curso, intitulado "O Papel da Interface Público/Privada na Vida Urbana - O Bairro da Torre, João Pessoa". Esse tipo de interface, de extrema importância na vida urbana por funcionar como a principal interconexão entre esses dois meios, é estudada à luz da urbanidade. Quando estruturas físico espaciais agem como promotoras de encontros, copresença e apropriação do espaço no âmbito público, a urbanidade é buscada através da adequação de dispositivos técnicos urbanos e disposições sociais por meio de intervenções urbanas. Assim, tem-se como objetivo estudar as dinâmicas de apropriação dessas interfaces, bem como propor novas perspectivas em termos de planejamento urbano. Para tal, diagnósticos de interfaces e atividades humanas no bairro em questão foram realizados a fim de serem melhor compreendidas e subsidiarem a proposta de intervenção para um de seus trechos.

Palabras clave: interface, público/privado, urbanidade, intervenções

Bloque temático: espacio público y proyecto urbano en la metrópolis contemporánea

\begin{abstract}
This article is derived from the author's paper, entitled "The Role of Public/Private Interface in Urban Life Neighborhood of Torre, João Pessoa". This type of interface, which is extremely important in the urban life for its function as the main interconnection between the two environments, which is studied in the light of urbanity. When good spatial physical structures act as developers of encounters, co-presence and appropriation of space in the public environment, the urbanity is pursued through urban interventions. Thus, the objective is to study the dynamics of appropriation of these interfaces, as well as to propose new perspectives in terms of urban planning. To this end, diagnoses of interfaces and human activities in the neighborhood in question were carried out in order to be better understood and to subsidize the intervention proposal for one of its stretches.
\end{abstract}




\section{Introdução}

O primeiro contato estabelecido ao caminhar pela cidade é o que se percebe ao nível dos olhos. A percepção da paisagem na escala da velocidade da caminhada, torna possível o estabelecimento de relações diretas entre o transeunte e o entorno: os detalhes construtivos podem ser vistos, as texturas podem ser sentidas, os obstáculos podem ser percebidos, o interior das lojas pode ser avistado. Ou seja, é onde o pedestre adquire noção da qualidade e dos problemas do espaço construído.

"A boa qualidade ao nível dos olhos deve ser considerada como direito humano básico sempre que as pessoas estejam nas cidades" (Gehl, 2013: 118). O que o urbanista Gehl trata por "qualidade ao nível dos olhos" está diretamente relacionado ao papel da interface público/privado. Hertzberger (1999: 32) define essa conexão entre meios como "o encontro e reconciliação entre a rua, de um lado, e o domínio privado, de outro", acrescentando ainda que as interfaces, a qual se refere como "intervalo", caracterizam-se como a sobreposição desses dois âmbitos, e não uma ruptura rígida entre eles. Desse modo, entende-se que a interface no meio urbano é a primeira relação estabelecida entre as diferentes funções do público e do privado, sendo a conexão fundamental entre esses diferentes usos, crucial para a qualidade da vida urbana.

É relevante esclarecer as definições de público e privado no contexto da arquitetura e urbanismo. Segundo Hertzberger (1999: 12), "pública é uma área acessível a todos a qualquer momento; a responsabilidade por sua manutenção é assumida coletivamente. Privada é uma área cujo acesso é determinado por um pequeno grupo ou por uma pessoa, que tem a responsabilidade de mantê-la", e apesar de genérica, essa definição é amplamente adotada. Para exemplificar, os espaços públicos estão relacionados às praças e ruas, e os espaços privados às residências e comércios. Contudo, pode-se existir ainda espaços de caráter misto, quando o uso privado se estende sobre os espaços públicos no desenvolvimento de determinadas atividades: por exemplo, no caso de bares e restaurantes, que se apropriam de calçadas com suas mesas e cadeiras, as quais o autor caracteriza como semipúblico ou semiprivado.

A promoção da qualidade da caminhada e da vida urbana em geral, por meio da interface público/privada, advém de diversos elementos vivenciados ao nível dos olhos, destacando-se neste trabalho quatro deles. Destinadas a acolher os transeuntes durante atividades universais de deslocamento e permanencia (Gehl, 2013), as calçadas possuem fundamental importância para a vivência em meio urbano. Estas tornam-se palco para que os pedestres percebam os demais dispositivos que integram a interface público/privada. Ademais, as calçadas, além de possuírem uma função física, possuem também uma função social, ao gerar segurança, ser cenário para interações entre vizinhos, passantes, ou ainda conflitos de apropriação e uso. Adjacente às calçadas, as áreas de transição definidas por Gehl (2013: 75) são os locais "onde a cidade encontra as edificações". Ao nível do pedestre, são as áreas da cidade destinadas aos acessos, à transição entre o privado e o público, tanto de pessoas como de suas atividades, em muitos casos sendo estas áreas equivalentes aos recuos dos lotes, previstos pelo Código de Urbanismo de João Pessoa (2001). São nesses espaços que as permeabilidades das edificações são percebidas. Sendo física ou visual estão presentes e podem ser entendidas como uma qualidade associada à vida urbana pública apta a garantir ou estreitar a relação física e visual entre as esferas pública e privada. Para Bentley (1985) as permeabilidades física e visual caracterizamse como a facilidade de adentrar e transitar no espaço e a capacidade do alcance visual neles, possibilitando um maior número de trocas entre os usuários.

Esses elementos construídos, chamados por Toussaint (2003) de DTSU ${ }^{1}$ - dispositivo técnico e espacial do urbano - equipam o espaço e remetem à materialização de práticas sociais, traduzindo-se em um conjunto de objetos fabricados, segundo o autor. A fabricação desses dispositivos associada aos usos dos mesmos caracteriza o que Joseph (1998) chama de disposições, ou "arranjos de visibilidade que só tem pertinência

\footnotetext{
${ }^{1}$ Do francês "dispositif techinique et spatial de l'urbain".
} 
em e por um momento de ação" (Joseph, 1998: 34), ou seja, só possuem significância quando atividades humanas acontecem. Para Gehl (1987), essas atividades podem ser classificadas em três categorias: necessárias, opcionais e sociais.

A relação entre dispositivos técnicos e disposições sociais é de extrema relevância para a elaboração da "urbanidade", conceito para o qual se atribui aqui grande importância, uma vez que remete a situações onde configuração espacial e sua mobilização social encontram-se em equilíbrio (Joseph, 2002) e graças às quais o "movimento contínuo de pessoas que confere vida ao tecido urbano" (Scocuglia, 2012: 80) é capaz de existir. Assim, entende-se a interface público/privada como um suporte à interação entre as dimensões espacial e social do espaço urbano; trata-se da superfície constituída por dispositivos técnicos, em torno dos quais articulam-se disposições sociais, durante a realização das atividades sociais urbanas. Pode-se dizer que a interface público/privada possui caráter crucial nas possibilidades de urbanidade de um lugar - sobretudo se o pensarmos como um espaço que acolhe as pessoas, com civilidade e cortesia (Aguiar, 2012).

Segundo Holanda (2013), a construção de uma "cidade sem ombro ou costas - só rostos" fundamenta-se no diálogo fértil entre edifícios e rua, na existência de interfaces eficientes, proporcionando uma dinâmica urbana ativa. Sua complexidade, dado os diversos elementos que a caracterizam, pode ser melhor entendida quando estes são observados e analisados detalhadamente, bem como de forma associada. Tais elementos subsidiarão decisões projetuais no cenário proposto, como forma de implementação de intervenções urbanas na escala das interfaces.

Para a cidade de João Pessoa, contexto no qual o estudo de caso está inserido, são diversas as formas que os dispositivos técnicos e as disposições sociais se associam e interagem na constituição das interfaces. Dentre fachadas cegas, e bairros com altos níveis de interação social em seus espaços públicos, ou ainda a implementação de ciclovias em importantes avenidas da cidade, João Pessoa é diversa no que tange às relações das interfaces público/privada com a vida urbana e às intervenções recentemente implementadas na cidade. O bairro Torre encontra-se nesse quadro de diversidade sócio espacial. Não sendo menor a sua importância histórica e morfológica para a cidade, a Torre destaca-se ainda por sua recente transformação no que diz respeito aos usos, tornando-se um importante subpolo de comércio e serviços para a cidade, mas que no entanto ainda preserva características tipológicas e sociais bastante características de uso residencial. Tal complexidade instigou a discussão do tema, bem como uma aproximação para a elaboração de proposta de intervenções.

Assim, este artigo pretende não apenas contribuir com a discussão sobre as interfaces público/privada, à luz do conceito de urbanidade, como também avançar no campo metodológico, testando novos instrumentos de leitura do espaço urbano. Neste sentido, a pesquisa fez uso de um protocolo de investigação rigoroso, fundamentado em um referencial teórico conceitual preciso, caracterizado por: registros in loco através de fotografias, mapeamento e intervenções digitais das imagens; confecção de cartografias e exploração dos mapas em softwares como QGis e Illustrator para análise do contexto nas quais as interfaces estão inseridas, delimitação do trecho em estudo e entorno imediato; e caracterização das atividades humanas, em tardes distintas durante e no fim de semana, a partir de técnicas de observação onde a presença da pesquisadora não fosse notada. $O$ corpus de pesquisa foi explorado a partir de categorias de análise quanto a presença $\mathrm{e}$ tipo de permeabilidades, calçadas, áreas de transição e atividades sociais, gerando assim matéria para reflexão e resultados que guiaram a elaboração de cenário de intervenção para as interfaces público/privadas do objeto de estudo.

O artigo está estruturado em quatro partes: primeiramente, é feita uma breve apresentação sobre alguns tipos de intervenções que podem contribuir na busca por maior urbanidade, seguido da explanação dos principais conceitos teóricos acerca da urbanidade e da interface adotados para este artigo, e os métodos utilizados para as etapas de diagnóstico. Em seguida, uma breve apresentação do bairro Torre é feita afim de introduzir 
os resultados do diagnóstico das interfaces e atividades humanas. Por fim, apresenta-se um cenário de intervenção com intuito de empregar os conceitos expostos e as considerações finais.

\section{Intervenções urbanas}

Afim de contextualizar as práticas atuais de urbanismo que contribuem para a busca de maiores índices de urbanidade pelo mundo, alguns conceitos serão apresentados antes de nos atermos aos conceitos de interface e urbanidade, norteadores desse trabalho. Um desses conceitos é o placemaking. Entendido como um conjunto de modalidades de intervenção urbana bottom-up, a transversalidade entre concepção, execução e gerenciamento colaborativos dos espaços assume importância significativa. Em particular, o planejamento envolvendo mediadores sociais e comunidades na definição, experimentação e consolidação dos usos dos espaços, em suas diferentes temporalidades, se sobressaem em relação às modalidades convencionais topdown de definição de partidos, formas e funções do espaço. Desse modo, o Project for Public Space (2007), afirma que o placemaking vai além das melhorias no desenho urbano e facilita a colaboração entre os usos, onde aspectos físicos, sociais e culturais definem um lugar e contribuem para sua evolução. A criação de espaços voltados para as demandas locais existentes, promovendo conforto e identificação por parte das pessoas através de melhorias fáceis e rápidas de serem aplicadas, experimentando possibilidades, é propósito também desse conceito.

O guia de desenho urbano "Urban Street Design Guide" (Nacto, 2013) traz, por sua vez, uma visão geral de princípios que cidades estão usando para tornar suas ruas mais seguras e convidativas às pessoas para atividades diversas, ou seja, criando espaços reais para pessoas nas cidades. Embasado na demanda das cidades em segurança, sustentabilidade, resiliência, multimodalidade e benefícios econômicos, o guia foca no desenho de ruas urbanas e espaços públicos, ao expor orientações e exemplos acerca de: ruas seguras e convidativas; elementos de controle de velocidade de vias; setorização de calçadas; e áreas de travessia seguras associadas a estratégias de drenagem pluvial.

\section{Referências teóricas e procedimentos metodológicos}

\subsection{Estrutura físico espacial}

As cidades são constituídas de inúmeras mudanças ao longo do tempo, sejam elas de maior ou menor dimensão, constantes ou não, elas buscam sempre atender às demandas dos diferentes interesses da sociedade. Dessa forma, podemos entender a cidade sob duas óticas distintas, porém indissociáveis. A cidade-produto caracteriza-se como resultado das modificações realizadas com base nos interesses dos atores sociais; em contrapartida, a cidade-estrutura age como modeladora das mudanças ao impor condicionantes, influenciando diretamente nas suas alterações (Figueiredo, 2012).

A interface público/privada caracteriza-se como um excelente exemplo dessa dualidade. Caracterizando-se como elemento de ligação entre meios opostos, ou superfícies de comunicação entre partes diversas, para o ponto de vista da cidade como resultado de processos (cidade-produto), as interfaces são consequências de interesses econômicos, de privacidade ou acessibilidade. Citem-se os comerciantes que optam por tipos de vitrines translucidas por exemplo, visando maior lucro para seus empreendimentos. As fachadas cegas de casas e condomínios aparecem nesta lógica como resultado de interesses particulares, os quais buscam privacidade e a ideia de segurança. Contudo, para que alterações nas interfaces sejam realizadas visando os diferentes interesses, estas devem ser submetidas às restrições impostas pelas legislações urbanísticas, à morfologia espacial, e a fatores climáticos ou culturais dos contextos em que estão inseridos. 
A construção das cidades, as quais sofrem atualmente um processo de homogeneização e isolamento, busca atender às demandas de quem consome (cidadãos, compradores) e produz cidades (incorporadoras, Estado), provocando reações em cadeia em dimensões diversas, nem sempre conhecidas pelos arquitetos ou consumidores (Netto et al 2017). A recorrente produção de edificações isoladas de seus entornos reflete diretamente no meio de interconexão que são as interfaces, as quais perdem seu caráter social de integração entre meios, e ficam submetidas a demandas de segurança, status e riscos de investimento, como trata Netto (2017).

Deve-se aqui conceituar a interface como o ponto integrador entre dois polos, o limiar entre opostos, onde se dá o acesso de um para o outro (Fig. 1). Essa articulação de transição, onde se pode ter conhecimento dos âmbitos público e privado simultaneamente é visto também nos estudos de Van Eyke (1962) sobre espaços in between, como uma alternativa arquitetônica para a reconciliação de espaços polares, como interior/exterior. Ao tratar as interfaces nessa dualidade supracitada (cidade produto/ cidade estrutura), onde também são influenciadas por fatores sociais, econômicos e de acessibilidade, essas conexões caracterizam-se como estruturas físico espaciais diretamente relacionadas à urbanidade. Desse modo, é perspicaz associar as interfaces às ações humanas, visto que para Joseph (1998) atividades sociais se desenvolvem graças ao grau de urbanidade associado a estruturas físico espaciais.

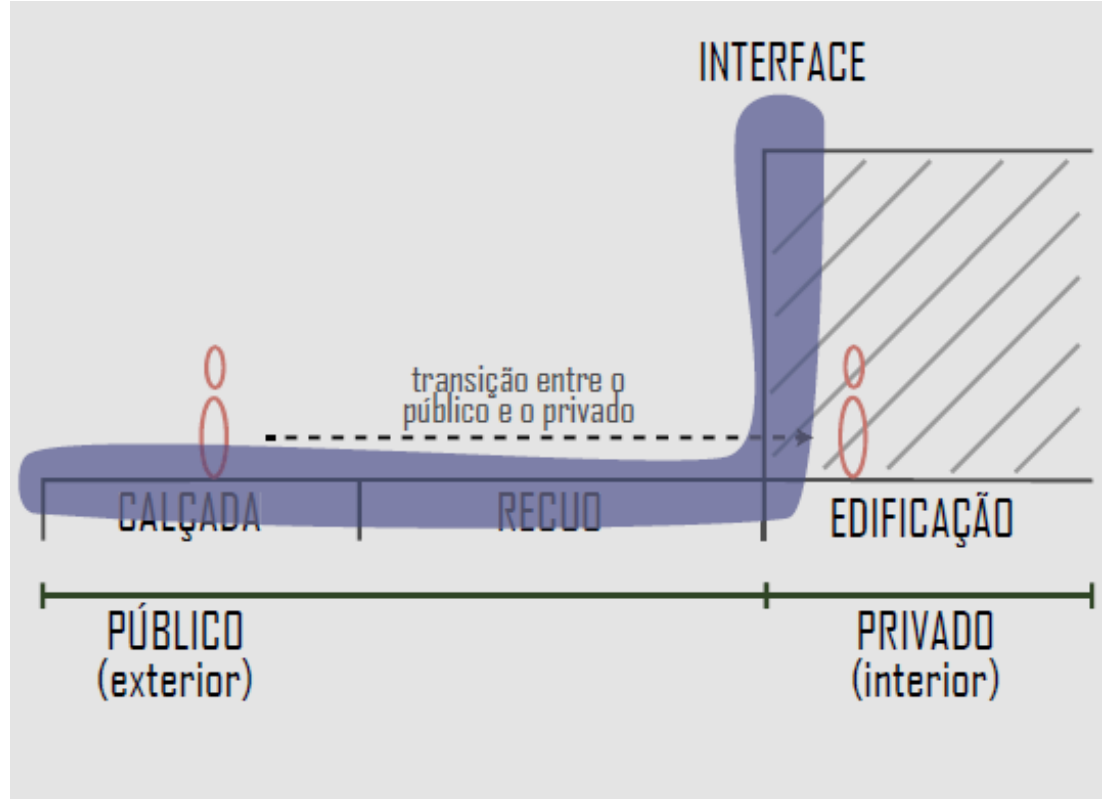

Fig. 1 Esquema explicativo de interface público/privado. Fonte: Aquino, 2018.

Faz-se importante esclarecer que por "urbanidade", compreende-se as "relações de civilidade e de cortesia, inseridas em uma dupla dimensão sócio espacial" (Trigueiro, 2010). Ou seja, a presença de dispositivos de socialização próprios às cidades exercem influência direta nas práticas sociais e nessas relações de civilidade, como também explicou Joseph (2002). Trata-se então de pensar na cidade como "instrumento de urbanidade" Joseph, 2002 apud Trigueiro e Santos, 2016: 367), ou seja, estando a vida social em desenvolvimento com o suporte adequado de uma estrutura físico espacial (Trigueiro e Santos, 2016: 366). Como componente dessas estruturas estão os DSTU, os quais caracterizam-se como a materialização das práticas sociais traduzindo-se em objetos fabricados, segundo Toussaint (2003). No entanto, esses dispositivos técnicos não devem ser dissociados das disposições sociais, do porquê de seus funcionamentos e disposições no espaço, com base nas necessidades e práticas sociais. É nessa relação de fabricação e usos que as intervenções urbanas se enquadram na produção da cidade, afim de corroborar a lógica que rege esses dispositivos e disposições nos 
contextos em que estão inseridos: promover autonomia das pessoas com os espaços para que a copresença, encontro e apropriação dos objetos às atividades sociais sejam possíveis de acontecer. Assim, algumas experiências de retomada dos espaços públicos, com intervenções notadamente voltadas às interfaces público/privada, e impactos significativos nas atividades humanas e dinâmicas da cidade foram destacadas neste trabalho.

\subsection{Métodos}

Afim de contextualizar os dispositivos técnicos e disposições sociais das interfaces, uma breve abordagem sobre o bairro da Torre se fez através da pesquisa bibliográfica acerca do contexto histórico, características gerais e usos, bem como produção cartográfica utilizando-se dos softwares Illustrator e QGis para localização do bairro e trecho em estudo.

A verificação dos DTSU aqui estudados e a representação do material coletado foram realizados com base na metodologia de análise de calçadas Safari Urbano (Cidade Ativa, 2018). A metodologia aborda elementos diversos que abrangem não só as calçadas mas também as fachadas, ao dividir-se em planos de análise: o plano do piso, o do edifício, o da cobertura e o da via. Contudo adaptações foram necessárias para esta pesquisa, focando-se nos planos do edifício e do piso. Foram então aplicadas classificações gerais para as permeabilidades das fachadas, podendo ser cegas (sem comunicação visual nem física); portas e janelas (acessos físicos e visuais); janelas, (apenas comunicação visual); portas (apenas acesso físico), segundo Donegan (2016:130); calçadas, classificadas em inexistente, caminhável sem obstáculos e caminhável com osbstáculos; e áreas de transição, sendo estas suaves ou rígidas em relação à destinação dos recuos dos lotes à pedestres ou não, respectivamente. Como modo de apreensão e representação desses elementos das interfaces, fez-se uso de fotografias sob a perspectiva dos transeuntes, intervenção digital sobre essas imagens, bem como a caracterização do seu entorno imediato.

Para a identificação das atividades humanas, visitas a campo foram realizadas no período da tarde (entre $13 \mathrm{~h}$ e 17h) em dias de semana e fins de semana, a fim de obter dados comparativos, visto que a presença de pessoas, assim como o uso dos dispositivos por elas podem variar de acordo com dias e horários. Para tal, as atividades foram classificadas segundo Gehl (1987) em: necessárias correpondendo a caminhada para o trabalho ou a espera do ônibus; opcionais caracterizando-se no exercício físico, contemplação da paisagem ou compras; e sociais, exemplificadas por crianças brincando, encontros ou rodas de conversas. Fotografias e mapeamento das atividades foram os recursos metodológicos utilizados nessa etapa.

\section{4. $O$ bairro da Torre, suas interfaces e principais atividades}

\subsection{Caracterização físico-espacial do bairro}

Localizado ao centro-norte da cidade de João Pessoa, o bairro Torre está delimitado por importantes vias conectoras da cidade, além de trecho da Mata Atlântica ao sul (Fig. 2). Sua formação e localização estratégica possuem valor histórico na formação atual do município. Oriundo do processo de expansão da cidade em direção à orla, teve seu traçado implementado na década de 1930 onde a malha urbana favorecia a ventilação e conexão a vias já existentes (Coutinho, 2004). Abrigando um dos primeiros conjuntos habitacionais, o caráter residencial sempre foi predominante. Porém o bairro vem sofrendo modificações quanto aos usos desde a criação da Av. Epitácio Pessoa na década de 1970, quando a cidade expandiu para o litoral, e desde então se tornou um importante subpolo comercial e de serviços, ao abrigar estabelecimentos para atender a população crescente das regiões adjacentes. Essas transformações do bairro são recorrentes ainda atualmente, e podem ser notadas face a redução demográfica e residencial, que corresponde à $4 \%$ segundo Lucena (2017) quando 
os anos de 2016 e 2017 são comparados. Atualmente o bairro destaca-se também por abrigar grandes centros médicos, mercados, comércios e serviços de empreendimentos automobilísticos e da construção civil.

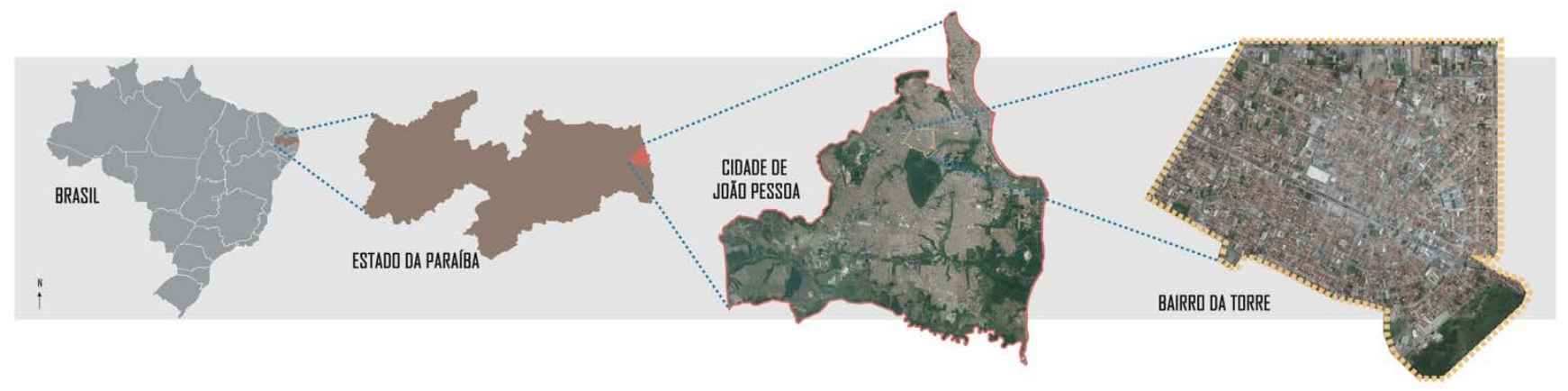

Fig. 2 Localização do Bairro da Torre em João Pessoa. Fonte: Elaboração própria.

\subsection{As interfaces e as atividades humanas}

A partir da compreensão do contexto geral em que o bairro está inserido, um diagnóstico de suas interfaces público/privadas e atividades humanas que nelas ocorrem foi elaborado. Afim de investigá-las e obter dados subsidiários para elaboração de um cenário, foram analisados dispositivos técnicos como calçadas, permeabilidades e áreas de transição, bem como disposições sociais caracterizadas por atividades de caráter social, necessárias ou opcionais, assim como os meios de transportes.

A avenida Rui Barbosa foi escolhida dentre quatro subrecortes analisados no trabalho de Aquino (2018). O trecho em estudo compreende uma área de comércio, serviços e comedoria, além de apresentar alguns lotes vazios e paradas de ônibus. No que se refere às interfaces público/privadas para essa área, as fachadas, de forma geral, se apresentam fisicamente e visualmente permeáveis, a não ser pela existência de alguns lotes que possuem muros opacos com apenas um acesso físico. Para os estabelecimentos comerciais e de serviço, vitrines são voltadas para a calçada, ora feitas de vidro transparente, ora sendo completamente abertas (Fig. 3).

A presença de toldos em alguns lotes evidencia espaços para se abrigar ou encostar, auxiliados ainda pelas reentrâncias e degraus existentes. Desse modo, as áreas de transição são em menor número destinadas a estacionamentos e em maior parte classificadas como suave, visto que as lanchonetes e algumas lojas reservam seus recuos para o abrigo de mesas para seus clientes ou exposição de suas mercadorias.

Para as calçadas desse trecho, a maioria apresenta-se como caminhável com obstáculos (desníveis, pavimentação deteriorada, rampas de acessos de veículos, estreitamento do passeio), salvo as que pertencem aos edifícios empresariais recém construídos ou reformados. Encontram-se ainda, nesse ponto, massas arbóreas esporádicas e iluminação pública em um dos lados da via. 


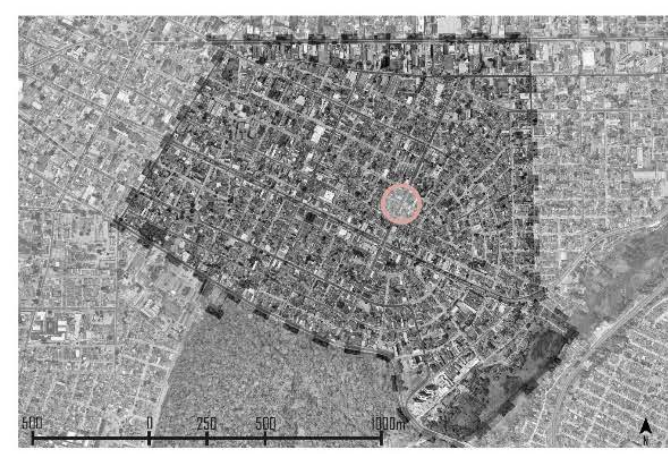

\section{LEGENDA}

\section{- LIMITE BAIRRO TORRE \\ PONTOS DE CAPTURA DAS INTERFACES}

PLANOS DA INTERFACE PÚBLICO/PRIVADO

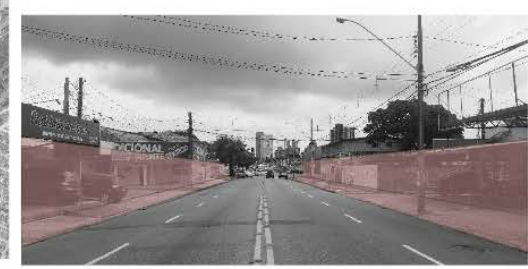

PONTO DE CAPTURA DE INTERFACE

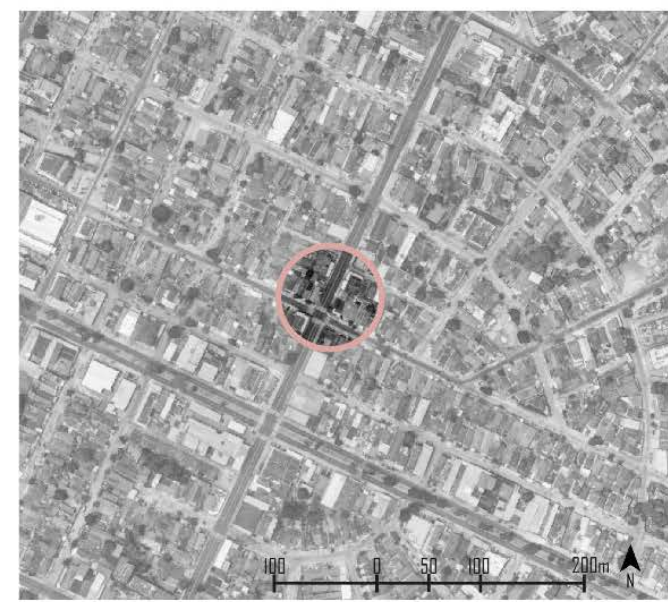

\section{LEGENDA}

Situação dAs CALÇADAS

CAMINHÁVEL COM OBSTÁCULOS

CAMINHÁVEL SEM OBSTÁCULOS

INEXISTENTE

PeRmeabilidade física e VISUAL

PORTAS

JANELAS ÁREAS DE TRANSIÇÃo

portas e Janelas SuAve

$\square$ MUROS CEGOS $\quad$ RÍGIDA

DISPOSITIVOS COMPLEMENTARES

(POSTES, PLACAS, FAIXAS DE PEDESTRES,

MOBILIÁRIO URBANO)
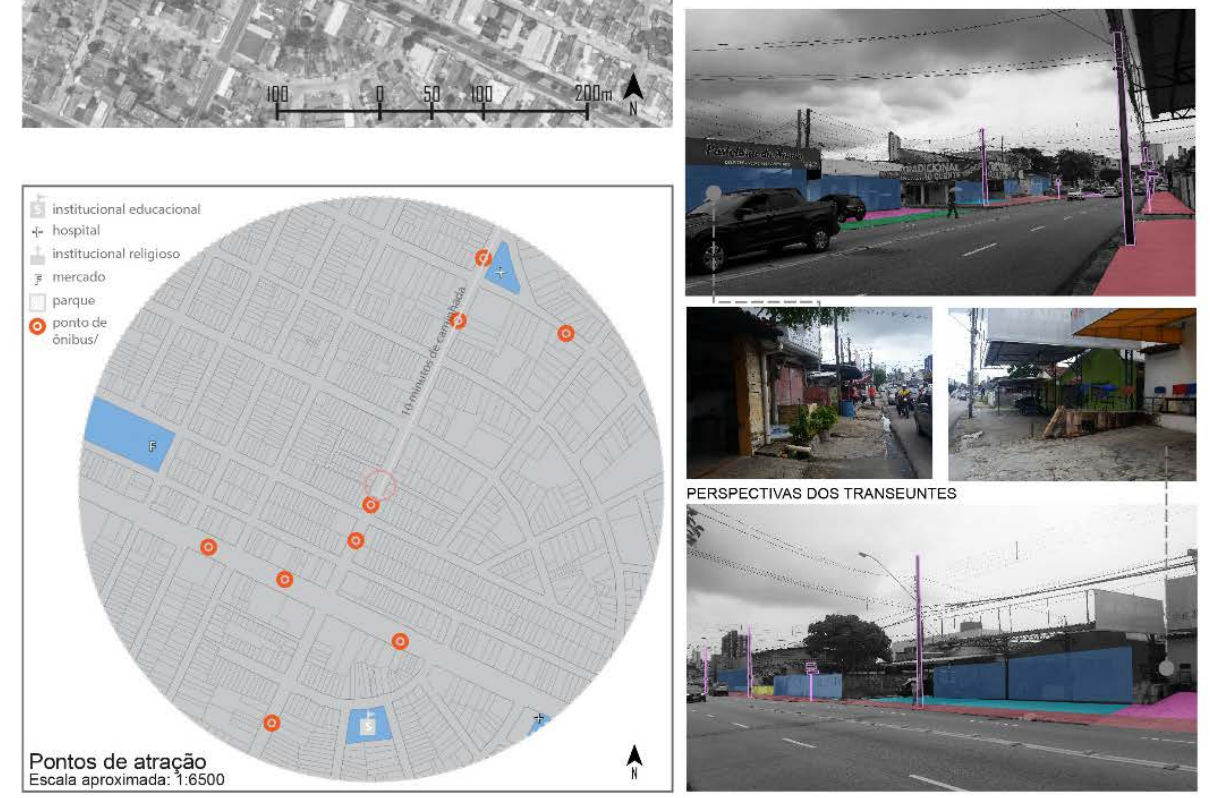

Fig. 3 Síntese do diagnóstico das interfaces. Fonte: elaboração própria.

Quanto às atividades humanas, observou-se para dias de semana a ausência de atividades sociais como encontros entre vizinhos, conversas ou contemplação, contudo atividades necessárias associadas às pessoas uniformizadas que iam/vinham do trabalho, por exemplo, foram percebidas, bem como pessoas que caminhavam até/desde a padaria, exercendo assim atividades opcionais (Fig. 4). 


\section{DIA DE SEMANA (TARDE)}

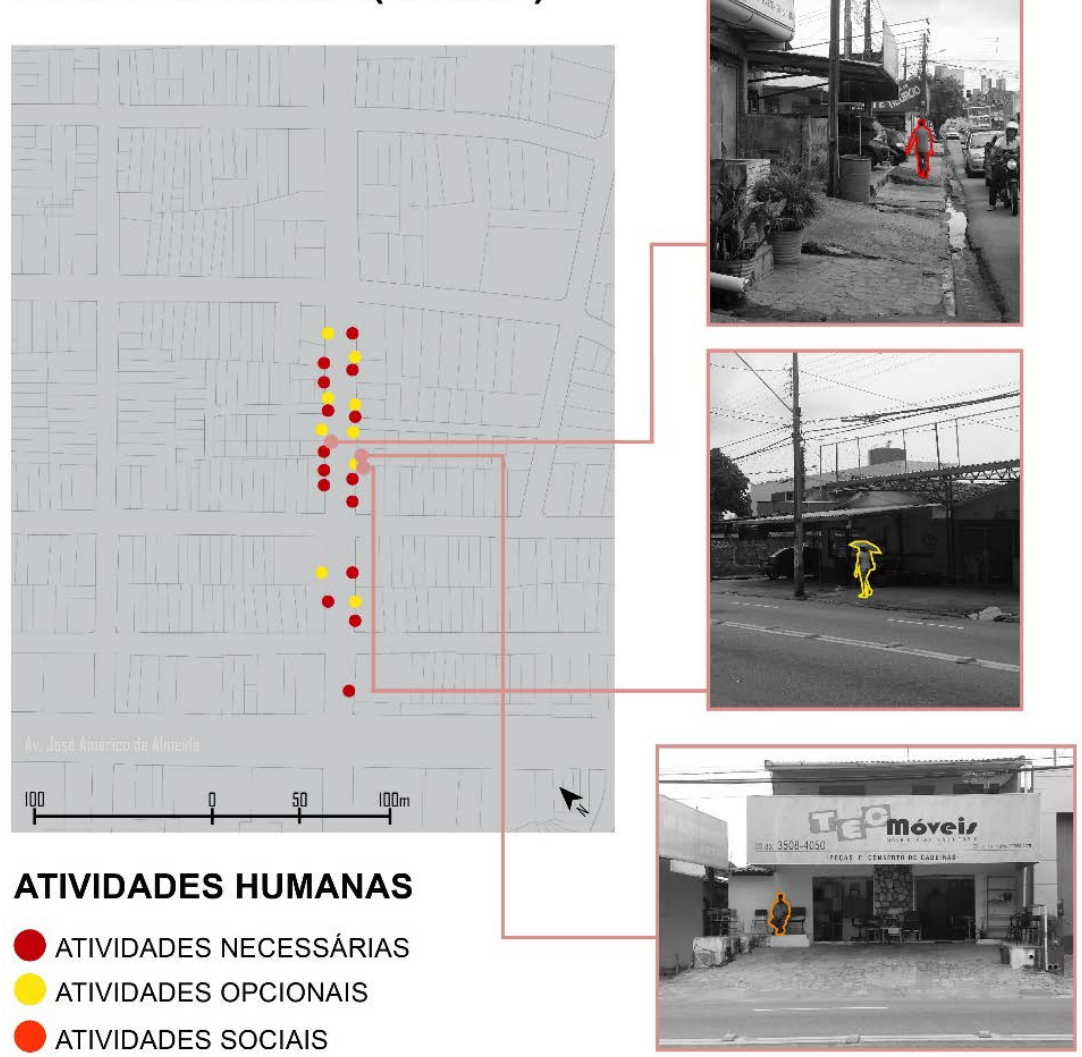

Fig. 4 Síntese do diagnóstico das atividades humanas em dias de semana. Fonte: elaboração própria.

O cenário distinguiu-se para as tardes do fim de semana, em que as atividades opcionais e sociais destacaramse. Essas atividades se deram em virtude de pessoas que passeavam com cachorro ou com crianças, exercitavam-se ou carregavam sacolas de compras, assim como por pequenos grupos de homens que bebiam e ouviam música em uma das esquinas, e mulheres que conversavam e brincavam com crianças em uma área de transição de uma lanchonete. Ficou ainda evidente o fluxo relevante de ciclistas, em todos os momentos da observação, ora por vendedores ambulantes, ora por pessoas que voltavam do trabalho ou exercitavam-se (Fig. 5). 


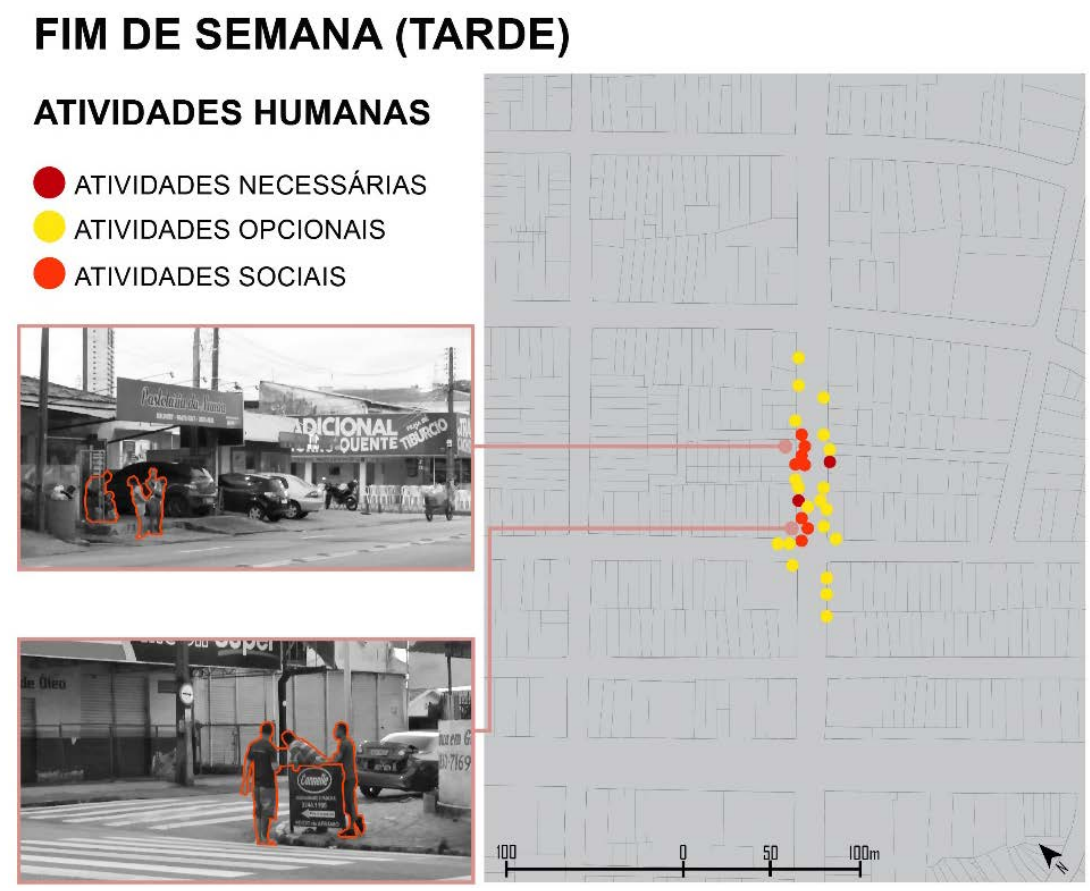

Fig. 5 Síntese do diagnóstico das atividades humanas no fim de semana. Fonte: elaboração própria.

\section{Cenários para o estudo de caso}

A proposta para o cenário foi pensada de modo a adotar intervenções urbanas, onde os espaços públicos são planejados como estimulantes à copresença e interações entre pessoas. Desse modo, a proposta busca espaços públicos vivos, promotores de atividades e encontros diversos. No cenário proposto, alguns redesenhos são sugeridos à fim de, juntamente com alterações tecnicamente simples, promover interfaces mais aprazíveis geradoras de maior urbanidade, além de tornar as ruas mais seguras para quem nelas transitam.

O PPS aponta algumas qualidades de um espaço público bem sucedido, sendo utilizadas algumas dessas referências para a sugestão das intervenções nesse cenário. Ademais, a proposta busca catalisar as potencialidades e propor soluções para os problemas do trecho em questão (Fig. 6). 


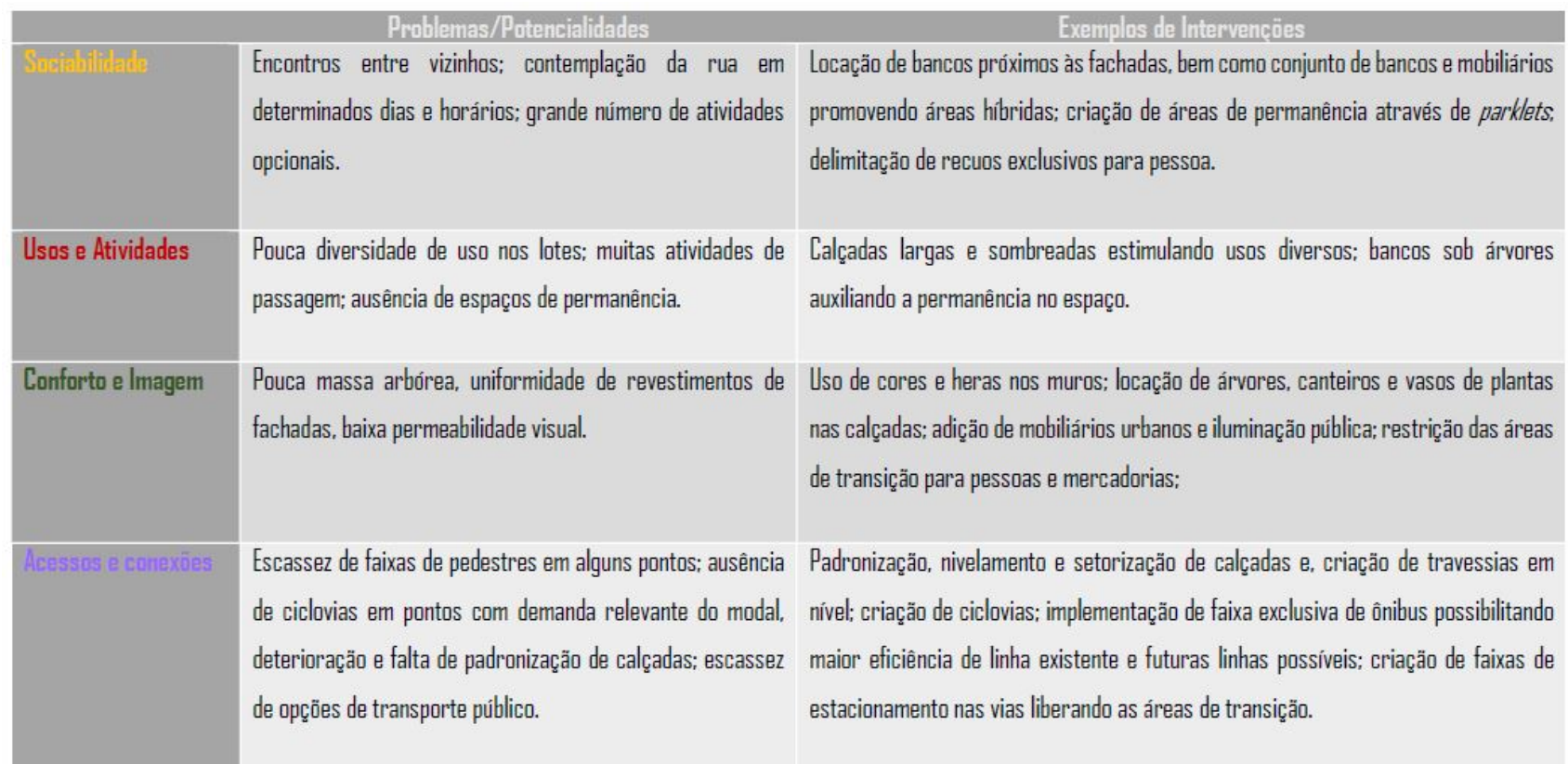

Fig. 6 Imagem de tabela síntese das qualidades do espaço, problemas/potencialidades e exemplos de intervenções. Fonte: Aquino, 2018.

A identificação de atividades sociais, sobretudo aos fins de semana, das atividades opcionais e dos estabelecimentos de comércio, serviço e comedoria, levaram à proposição de dispositivos técnicos e disposições sociais que fomentassem tais características locais. Assim, de maneira geral, no que tange às propostas de desenho urbano, a redução para duas faixas de rolamento possibilitou a criação de faixa exclusiva para ônibus, ciclovia e faixa de estacionamento na via. Tais ações refletem na redução da velocidade dos carros, na eficiência da linha de transporte público existente e de possíveis futuras linhas, bem como no atendimento à demanda do modal bicicleta e na liberação dos recuos para pedestres em detrimento aos carros (Fig. 7, Fig. 8 e Fig. 9).

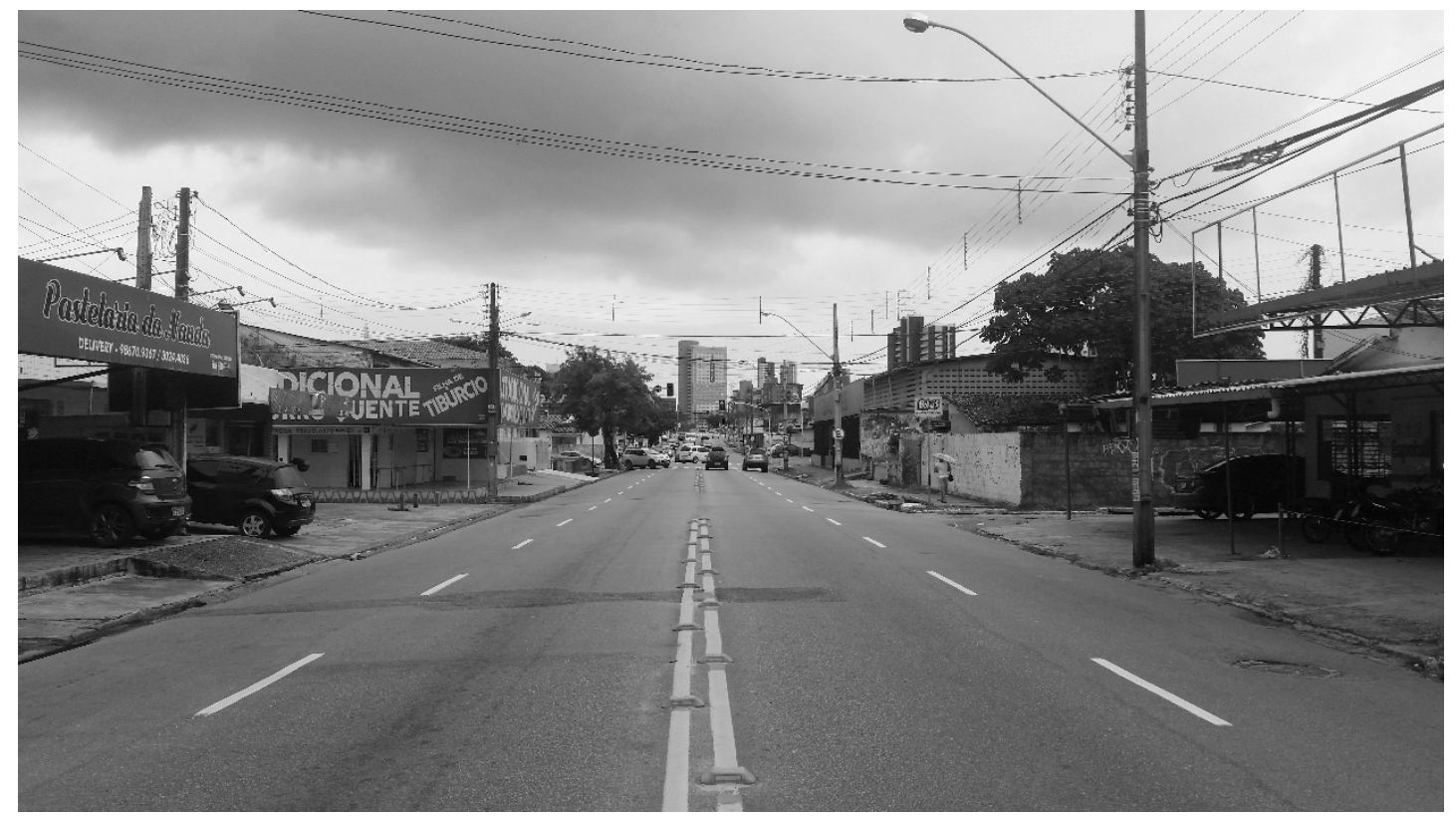

Fig. 7 Situação atual Av. Rui Barbosa. Fonte: elaboração própria. 


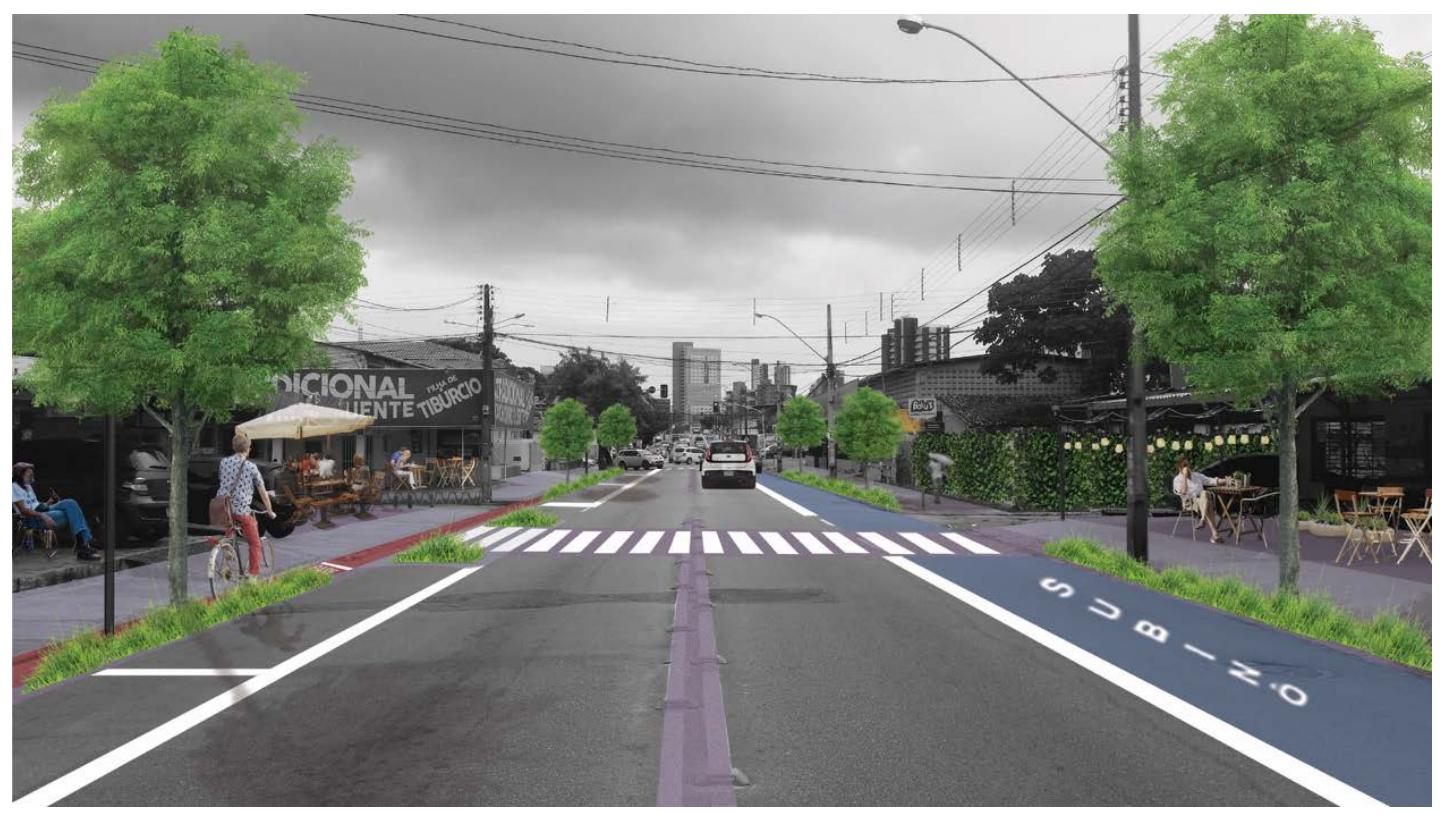

Fig. 8 Proposta de cenário para a avenida Rui Barbosa. Fonte: elaboração própria.

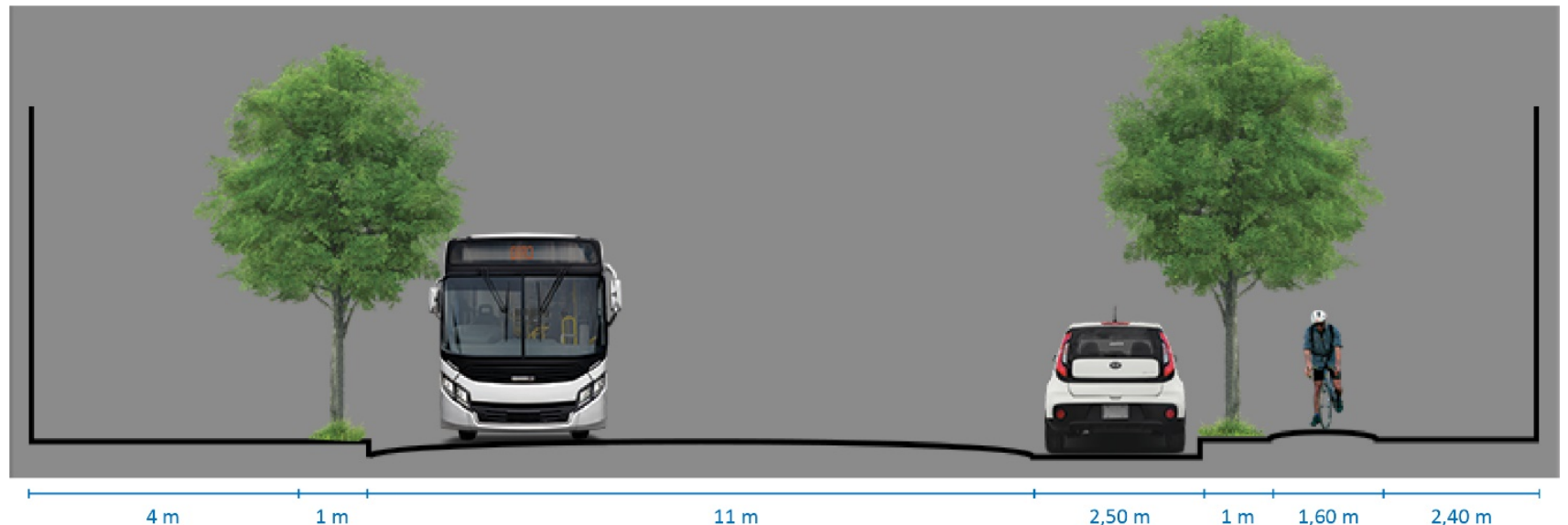

Fig. 9 Perfil esquemático da proposta. Fonte: elaboração própria.

Calçadas foram padronizadas e setorizadas, possibilitando a locação de mobiliário, canteiros e arborização. Intervenções tecnicamente simples utilizando-se de cores, heras, jarros e bancos juntos às fachadas foram propostas. Foi proposto também destinação exclusiva das áreas de transição a pessoas e mercadorias, através de usos de cores similares entre fachadas e recuos, roseiras e iluminação ao nível dos olhos. Fez-se uso também de pisos diferentes entre si, locação de mesas e expositores, além da instalação de vasos de plantas como barreiras delimitadoras dessas áreas (Fig. 10). 


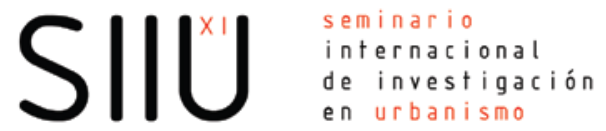

barcelona|santiago de chile junio 2019

DOI: $10.5821 /$ SIIU.6643

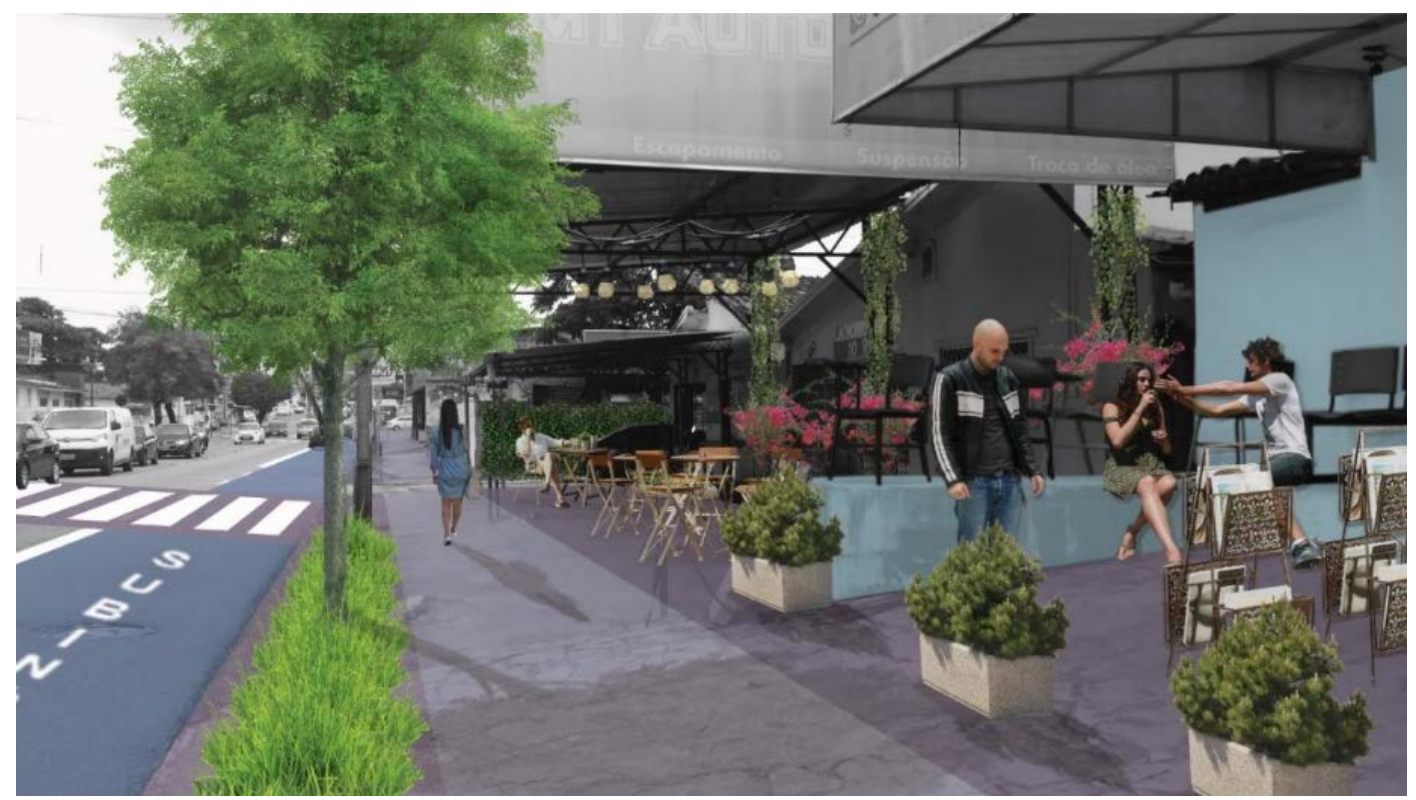

Fig. 10 Proposta de cenário para a avenida Rui Barbosa. Fonte: elaboração própria.

\section{Considerações Finais}

Este artigo põe em evidencia um elemento da vida urbana o qual nem sempre recebe atenção necessária. A interface público/privada como principal meio de interconexão entre espaços privados e públicos está presente no dia a dia de uma cidade e exerce grande influência nas atividades sociais diárias. Da perspectiva da urbanidade, as fabricações e usos, ou seja, dispositivos técnicos e disposições sociais (calçadas, permeabilidades, áreas de transição, atividades humanas) que as compõe intervêm para que encontros, apropriações do espaço e copresença ocorram.

O processo de urbanização atual, pelo qual diversas cidades brasileiras vem passando, baseado quase que exclusivamente no atendimento de demandas de consumidores e produtores da cidade (status sociais, critérios de segurança e riscos de investimento) tem levado a produção de interfaces rígidas e pouco integradas ao meio no qual estão inseridas. Dessa forma, as interfaces estão perdendo importantes características, como sua função social, de conexão, de acolhimento, e de espaços intermediários de articulação como trata Van Eyck, (1962).

Não sendo diferente, João Pessoa passa por esse processo. Acrescenta-se que uma diversidade de arranjos entre dispositivos técnicos e disposições sociais são nela encontrados. Nesse cenário está o bairro da Torre, que passa ao longo dos anos por um processo de crescimento de usos comercial e de serviço, constituindo hoje um importante subpolo para a cidade. Tal fato é diretamente refletido na forma como suas interfaces estão constituídas e vêm se modificando, bem como na forma que seus habitantes ocupam o bairro, por muitas vezes conservando ainda características de bairros residenciais tradicionais.

É afim de promover boa qualidade às estruturas físico espaciais (interface público/privada), que as intervenções urbanas estão aqui associadas. Conceitos do desenho urbano e ideias do placemaking melhoram não apenas aspectos físicos, como os dispositivos já citados, mas também sociais. É buscando maiores índices de urbanidade e valorização da função do espaço público baseada na tríade de coopresença, apropriação e encontros, que um cenário foi proposto para o bairro da Torre. 
Em âmbito internacional, a pesquisa traz à tona a reflexão sobre as interfaces público/privadas como estruturas inerentes à vida urbana e influenciadoras direta para existência da urbanidade das cidades. As intervenções urbanas enquadram-se então na discussão ao tratarem conceitos e técnicas plausíveis a serem utilizadas para aumentar índices de urbanidade e constituir cidades saudáveis face aos recentes processos de urbanização.

\section{BIBLIOGRAFÍA}

AGUIAR, D. V. (2012). Urbanidade e a qualidade da cidade. En: D. AGUIAR et al, Urbanidades (52-68). Rio de Janeiro: Letra \& Imagen.

AQUINO, C. B. (2018). O Papel da Interface Público/Privado na Vida Urbana. O Bairro da Torre, João Pessoa. João Pessoa: UFPB.

BENTLEY, I. (1985). Responsive environments: A manual for designers. London: Routledge.

COUTINHO, M. A. F. (2004). Evolução urbana e qualidade de vida: o caso da avenida Epitácio Pessoa. João Pessoa: UFPB.

DONEGAN, L. (2016). Qual é a sua praia. Arquitetura e sociedade em praias de Natal-RN. Natal: UFRN.

FIGUEIREDO, L. (2012). Desurbanismo: um manual rápido de destruição de cidades. En: D. AGUIAR et al, Urbanidades (175- 196). Rio de Janeiro: Letra \& Imagen.

GEHL, J. (2013). Cidade para pessoas. São Paulo: Perspectiva.

GEHL, J. (1987). Life between buildings: using public space. Washington: Island Press.

HEEMANN, J. y SANTIAGO, P. (2015). Guia do Espaço Público para inspirar e transformar. São Paulo: Conexão Cultural.

HERTZBERGER, H. (1999). Lições de arquitetura. São Paulo: Martins Fontes.

HILLIER, B. et al. (1993). Natural movement: or, configuration and attraction in urban pedestrian movement. En: Environment and Planning B: planning and design (29-66). London: University College London.

HOLANDA, F. (2013). Os dez mandamentos da arquitetura. Brasília: FRBH.

JACOBS, J. (2009). Morte e vida de grandes cidades. São Paulo: WMF Martins Fontes.

JOSEPH, I. (1998). Paysages urbains, choses publiques. En : I. JOSEPH. La ville sans qualités (5-25). Paris : l'Aube.

JOSEPH, I. (2002) Espace public, urbanité, citoyenneté. En: M. JOLE. Espaces publics et cultures urbaines. Actes du séminaire du CIFP de Paris 2000-2001-2002 (33-42). Lyon: CERTU.

LYDON, Mike et al. (2012). Tactical urbanism 1. Short-term action, long-term change. New York : Street Plans Collective.

LUCENA, E. Victor P. (2017). Bairro da Torre - Diagnóstico e Proposta para um Planejamento Urbano (mais) Sustentável. João Pessoa: UFPB.

NACTO (2013). Urban Street Design Guide. Nova lorque: Island Press.

NETTO, V. et al. (coord.) (2017). Efeitos da Arquitetura: os impactos da urbanização contemporânea no Brasil. Brasília: FRBH. 
NETTO, V. M. (2017). A cidade como resultado: consequências de escolhas arquitetônicas. En: V. NETTO et al. (coord.). Efeitos da Arquitetura: os impactos da urbanização contemporânea no Brasil (25-49). Brasília: $\mathrm{FRBH}$.

SCOCUGLIA, J. B. C. (coord.) (2012). Cidade, cultura e urbanidade. João Pessoa: Editora Universitária da UFPB.

TOUSSAINT, J. Y. (2003). Projets et usages urbains. Fabriquer et utiliser les dispositifs techniques et spatiaux de l'urbain. Lyon: INSA.

TRIGUEIRO, M. (2010). Pacificação da cidade: a urbanidade legitimada. In: AGUIAR, Douglas et al. Urbanidades (81-113). Rio de Janeiro: Letra e Imagem.

TRIGUEIRO, M. y SANTOS, M. D. V. (2016). Urbanidade Reconquistada? Transformações fisicoespaciais e sociais em Mangabeira, João Pessoa, Estado da Paraíba, Brasil. En: G. J. A. SILVA, M. D, SILVA y J. A. R. SILVEIRA. Lugares e suas Interfaces Intraurbanas: Transformações Urbanas e Periferização (360-387). João Pessoa: UFPB.

VAN EYCK, A. (1962). Steps toward a configurative discipline. En: Fórum de Arquitetura e Artes Relacionadas (81-94). Amsterdam: Hilversum

\section{Fuentes Eletrónicas:}

https://cidadeativa.org/iniciativa/safaris-urbanos/ (Consulta: 10/05/2018).

https://www.pps.org/article/what-is-placemaking (Consulta15/05/2019). 